\title{
Refractory Hodgkin's Disease Lymphocyte Predominance Type
}

National Cancer Institute

\section{Source}

National Cancer Institute. Refractory Hodgkin's Disease Lymphocyte Predominance

Type. NCl Thesaurus. Code C8829.

An antiquated term that refers either to nodular lymphocyte predominant Hodgkin lymphoma or to lymphocyte-rich classical Hodgkin lymphoma that is resistant to treatment. 